\title{
Molecular Identification of Selected Multiple Antibiotic Resistance Bacteria Isolated from Poultry Droppings in Akure, Nigeria
}

\author{
Kehinde Oluyemi Ajayi ", Funmilola Oluyemi Omoya \\ Department of Microbiology, Federal University of Technology, Akure, Nigeria \\ Email address: \\ ooluyhemikehinde@yahoo.com (K. O. Ajayi),fomoya@yahoo.com (F. O. Omoya) \\ ${ }^{*}$ Corresponding author
}

\section{To cite this article:}

Kehinde Oluyemi Ajayi, Funmilola Oluyemi Omoya. Molecular Identification of Selected Multiple Antibiotic Resistance Bacteria Isolated from Poultry Droppings in Akure, Nigeria. Biochemistry and Molecular Biology. Vol. 2, No. 1, 2017, pp. 6-11.

doi: $10.11648 /$ j.bmb.20170201.12

Received: February 27, 2017; Accepted: March 8, 2017; Published: March 22, 2017

\begin{abstract}
Molecular techniques have the advantage that, they are rapid, less laborious, and more sensitive, specific and efficient compared to the conventional method of bacteria identification. This work aimed at Molecular Identification of Selected Multiple Antibiotic Resistance Bacteria Isolated from Poultry Droppings in Akure, Nigeria. Samples were plated on selective and differential media. Isolation and identification of bacteria were carried out using standard microbiological method, Antibiotics susceptibility test was determined by the disk diffusion method, Plasmid DNA extraction, profiling and curing, Genomic DNA extraction, Polymerase Chain Reaction (PCR), agarose gel electrophoresis, 16S rRNA gene sequence and phylogenetic analysis were carried out by standard method. Eight bacteria were selected; Proteus mirabilis, Salmonella typhi, Pseudomonas aeruginosa, Staphylococcus aureus, Salmonella sp. Escherichia coli, Shigella sp. and Klebsiella pneumonia, they were resistant to at least seven antibiotics. The result revealed that the plasmid size ranged from 8.60 to 128.00 kilobase pair $(\mathrm{kbp})$ and the number of plasmid carried by bacteria ranged from 1 to 3 plasmids. Based on the 16s rRNA sequences, the following bacteria were identified Salmonella enterica subsp.enterica serovar Typhi str. CT18, Proteus mirabilis strain HI4320, Pseudomonas fluorescens SBW25, Staphylococcus cohnii subsp. cohnii strain 532 Contig16, Salmonella enterica subsp. enterica serovar Infantis, Escherichia coli str. K12 substr. DH10B, Shigella flexneri 2a str. 2457T and Klebsiella pneumoniae strain J1. The presence of multiple resistant bacteria and plasmid mediated resistance of human pathogenic bacteria isolated from poultry droppings in Akure is of great public health importance.
\end{abstract}

Keywords: Bacteria, Molecular Identification, Antibiotics, Plasmid

\section{Introduction}

In recent times, several foodborne pathogens of poultry origin have become important and a threat to public health. Surveillance studies have provided data and a better understanding into the existence and spread of foodborne pathogens. The survival of foodborne pathogens under a variety of environmental conditions warrants the development and use of efficient and reliable isolation, detection, differentiation, classification and/or typing techniques for their surveillance $[1,2]$.

In reality, increasing resistance levels among pathogenic bacteria are driven by antibiotic use in all sectors: in humans, in the community and in hospitals, on farms and in companion animals. Although resistance in human infections is mainly caused by human antibiotic use, for a range of bacteria, farm-animal use contributes significantly and for some infections is the main source of resistance. Antibioticresistant bacteria pass between humans, between animals and between humans and animals in both directions mostly through the food chain much more frequently than once realised. Copies of antibiotic-resistance genes can also move between bacteria, and this exchange can occur in the human gut, so in some cases the bacteria causing a human infection will not be of farm-animal origin, but the resistance will be $[3,4,5]$.

Ever growing global migratory trend, rapid industrialization and extensive growth in poultry production 
are thought to contribute the possible rapid dissemination of zoonotic pathogens posing public health a potential concern [6] and a big threat.

During research, it is of utmost importance to identify unknown bacteria if diversity is being studied. One of the main responsibilities is to determine the identity of pathogenic bacteria. Bacterial identification by diagnostic laboratories is based on phenotypic characteristics involves a few simple tests such as morphology, growth on various types of culture media and biochemical tests [7]. They are widely used and have the advantage that, they are cheaper, detect only viable bacteria, and yield isolates that can further be characterised and studied [1]. However, they are laborious, relatively slow and less efficient while Molecular techniques have also been widely used in surveillance, mutation and other genetic studies of foodborne pathogens to increase our understanding into the primary source of foodborne pathogens, source of infection and genetic diversity. Molecular techniques have the advantage that, they are rapid, less laborious, and more sensitive, specific and efficient compared to the conventional method [8,9]. In developing countries where antibiotic resistance is a prime issue, data are least available $[10,11]$. Thus, it became imperative to provide information on the molecular identity of multiple antibiotic resistant bacteria isolated from poultry droppings in Akure metropolis.

\section{Materials and Methods}

\subsection{Sample Locations}

Akure is the largest city and capital of Ondo State, located in south-west Nigeria. Akure lies about $70^{\circ} 15$ north of the equator and $50^{\circ} 15$ east Meridian. The city has a population of 588,000 which is $0.305 \%$ of Nigeria population based on 2006 population census; the people are of Yoruba ethnic group and are situated in the tropic rainforest. The city is a trade center for farmers where cocoa, bananas, palm oil, yams, cassava, corn, cotton and tobacco are mostly cultivated, the residents also engaged in various economic activities such as trading, transportation business, civil service and education. During this research, samples of poultry droppings were collected from nine (9) different locations in Akure metropolis.

\subsection{Sample Collection}

Six hundred and eighty four (684) samples of fresh poultry dung (layers and broilers) were collected from commercial poultry farms in nine (9) different locations (FUTA, Aba, Apatapiti, Ijoka, Oritaobele, Ado road, Ondo road, Alagbaka, and Lafe), while that of free range chicken was collected from chicken feeding ground at different locations in Akure, Ondo State, Nigeria. One gram of poultry dropping was collected in sterilised Mac Cartney bottle that contained peptone water and transported to Microbiology Research Laboratory of Federal University of Technology Akure within one hour of collection for bacteriological analysis. The samples were collected between November 2015 and January 2016.

\subsection{Isolation of Bacteria from Poultry Droppings}

Bacteriological examinations were carried out using standard methods for aerobic bacteria (Brown, 2005). Sample collected in Mac Cartney bottle was gently shake and stirred with sterile glass rod until the dung mixed thoroughly, aliquot $(1.0 \mathrm{ml})$ was transferred into the test tube containing $9.0 \mathrm{ml}$ of sterile distilled water and diluted serially in one-tenth stepwise to $10^{-7}$ dilution factor and $1.0 \mathrm{ml}$ each of dilution $10^{-}$ $5,10^{-6}$ and $10^{-7}$ was pure plated on Nutrient agar and some selective and differential media (Salmonella Shigella agar, Eosine Methyline Blue agar, MacConkey agar, Manitol salt agar and Cysteine Lactose Electrolyte Deficient agar), the plates were inverted and incubated aerobically at $37{ }^{\circ} \mathrm{C}$ for 24 hours after which the plates were examined for growth.

\subsection{Biochemical Characterization}

Biochemical characterisation and presumptive identification of isolates were carried out as described by [12].

\subsection{Antibiotics Susceptibility Test}

Antibiotics susceptibility test of all the isolates was determined by the disk diffusion method and interpreted as susceptible, intermediate and resistant as described by [13]. Gram negative pathogens were tested against the following antibiotics; Tetracycline (30 $\mu \mathrm{g})$, Ofloxacin $(30 \mu \mathrm{g})$, Gentamicin $(20 \mu \mathrm{g})$, Chloramphenicol $(30 \mu \mathrm{g})$, Augmentin $(30 \mu \mathrm{g})$, Ceftriazone $(30 \mu \mathrm{g})$, Nitrofuratoin $(300 \mu \mathrm{g})$, Cotrimoxazole $(25 \mu \mathrm{g})$, Ciprofloxacin $(10 \mu \mathrm{g})$ and Amoxicillin $(30 \mu \mathrm{g})$ while gram positive isolate were tested against Cotrimoxazole $(25 \mu \mathrm{g})$, Erythromycin $(10 \mu \mathrm{g})$, Gentamicin $(20 \mu \mathrm{g})$, Augmentin $(30 \mu \mathrm{g})$, Streptomycin $(10 \mu \mathrm{g})$, Cloxacilin $(5 \mu \mathrm{g})$ Tetracycline $(30 \mu \mathrm{g})$ and Chloramphenicol $(30 \mu \mathrm{g})$.

\subsection{Plasmid DNA Extraction, Profile and Curing}

Overnight growth of multidrug resistance bacteria broth culture was used for the plasmid isolation. TENS protocol describe by [14] was employed in plasmid extraction. $1.5 \mathrm{ml}$ of overnight culture was Spin for 1 minute in a microcentrifuge to pellet cells. Followed by gentle decant of the supernatant leaving $50 \mu \mathrm{l}$ together with cell pellet and vortex mixed at high speed to re-suspend cells completely. $300 \mu$ of TENS was then added. An inverting tube was used to Mix for 3 times until the mixture becomes sticky. $150 \mu$ of $3.0 \mathrm{M}$ sodium acetate $(\mathrm{pH}$ 5.2) was then added to the preparation, followed by Vortex mixing. The preparation was spun for 5minutes in micro-centrifuge to pellet cell debris and chromosomal DNA and then the supernatant was transferred into a fresh tube; and mixed well with $900 \mu \mathrm{l}$ of ice-cold absolute ethanol. It was then spun again for 10 minutes to pellet plasmid DNA. (White pellet is observed) after which the supernatant was discarded; the pellet was rinsed twice with $1 \mathrm{ml}$ of $70 \%$ ethanol and dry pellet. Pellet was re- 
suspend in $30 \mu \mathrm{l}$ of buffer or distilled water for further use. The extracted plasmid DNA was electrophoresized on $0.8 \%$ agarose gel stained with ethidium bromide in $10.0 \mathrm{ml}$ Trisacetate buffer and visualized by UV-transillumination according to Gamal, et al., (2014). (TENS composition: Tris $25 \mathrm{mM}$, Ethyl-dimethyl tetra-amine; EDTA $10 \mathrm{mM}$, Sodium hydroxide; $\mathrm{NaOH} 0.1 \mathrm{M}$ and Sodium dodecyl sulphate; SDS $0.5 \%$.). The controls used were molecular weight marker labeled M2 for examination of mega plasmids and molecular weight marker labeled M1 was used as control for evaluation of micro plasmids. The fragment bands observed were directly compared with the molecular weight marker bands. Plasmid curing was done by exposing the overnight grown culture at $37^{\circ} \mathrm{C}$ and $2 \%$ Sodium Dodecyl Sulphate (SDS). The isolate was further subjected to antibiotic sensitivity.

\subsection{Molecular Identification of Multiple Antibiotic Resistant Bacteria}

This test was carried out according to the method of [15], as follow:

(i) Genomic DNA extraction

$1.5 \mathrm{ml}$ of multidrug resistant bacterial broth culture was taken in centrifuge tube. Centrifuged at 10,000 rpm for 2 minutes and supernatant was discarded. To the pellet $1 \mathrm{ml}$ of distilled water was added and dissolved the pellet completely. Again centrifuged at $10,000 \mathrm{rpm}$ for $2 \mathrm{~min}$, the procedure was repeated for two times. The supernatant was discarded and to the pellet $100 \mu$ l of Tris EDTA buffer was added and dissolve the pellet completely in buffer. The supernatant containing the DNA were transferred to another tube and stored at $-20^{\circ} \mathrm{C}$. The concentration and purity of the extracted DNA was estimated using a Nanodrop spectrophotometer (Model: 752).

(ii) Polymerase Chain Reaction (PCR) amplification and purification of $16 S$ rRNA gene

The 16S rRNA gene was amplified using primers 5'AGAGTTTGAT CCTGGCTCAG 3' and 5'GACGGGCRGTGWGTR CA 3' forward and reverse respectively. PCR mix contained $10 \mathrm{X}$ buffer, $100 \mathrm{mM}$ dNTPs, 2.52M MgCl2, 2UTaqDNA polymerase, $1 \mu$ l of each (forward and reverse) primers, $2 \mu \mathrm{l}$ of genomic DNA and sterilized distilled water to make a final volume of $25 \mathrm{ml}$. TaqDNA polymerase initiates replication of DNA fragment by using nucleotide bases from dNTPs mixture (A, C, G, T). The PCR reaction included the following steps; initial denaturation of 2 min at $94^{\circ} \mathrm{C}$ (Pre heating) followed by 25 cycles were run on a thermal cycler, each comprising $1 \mathrm{~min}$ at $94^{\circ} \mathrm{C}$ (denaturation), $1 \mathrm{~min}$ at $94^{\circ} \mathrm{C}$ (annealing) and $1.5 \mathrm{~min}$ at $94^{\circ} \mathrm{C}$ (extension), followed by a final extension of $10 \mathrm{~min}$ at $94^{\circ} \mathrm{C}$ for utilization of extra dNTPs in the PCR mixture.

(iii) Agarose gel electrophoresis

$0.8 \mathrm{~g}$ of agarose was weighted and taken in a $100 \mathrm{ml}$ reagent bottle. To this $100 \mathrm{ml}$ of $1 \mathrm{X}$ TBE buffer was added and it was heated in microwave oven till agarose melts. The agarose solution was then poured in a gel-casting unit assembled with appropriate comb and it was allowed to get polymerize. When the agarose polymerized, the comb was removed and the gel was kept in electrophoresis tank consisting of 1X TBE buffer. About $2 \mathrm{ml}$ of isolated bacterial genomic DNA from PCR product was mixed with $2 \mathrm{ml}$ of loading dye (bromophenol blue) and it was loaded in $0.8 \%$ agarose gel. The gel was electrophoresed at 100 volts for about 30 minutes and it was observed on UV transilluminator.

(iv) $16 S$ rRNA gene sequence, BLASTn and phylogenetic analysis

Identification of strain was done by $16 \mathrm{~S}$ rRNA sequence analysis using sequencer, determined sequences were compared with sequences available in GeneBank, derived sequence aligned by Basic Local Alignment Search Tool (BLAST) algorithm, the highest S-ab value with identified species in the Sequence match search. Using the results received through BLASTn a phylogenetic tree is created using the BLASTn web-page.

\section{Result}

\subsection{Bacterial Isolated from Poultry Droppings in Akure}

Total number of one hundred and fifty seven (157) bacterial pathogens was isolated and based on biochemical characterization, they were identified as; Escherichia coli, Klebsiella oxytoca, Klebsiella pneumonia, Proteus mirabilis, Proteus vulgaris, Enterobacter aerogenes, Salmonella typhi, Salmonella spp., Shigella sonnei, Citrobacter freundii, Citrobacter diversus, Serratia marcescens, Pseudomonas aeruginosa, Staphylococcus epidermidis, Staphylococcus aureus, Bacillus subtilis, Bacillus cereus and Micrococcus luteus.

Based on antibiotic resistance profile and medical importance, the following eight bacteria were selected for further study; Proteus mirabilis, Salmonella typhi, Pseudomonas aeruginosa, Staphylococcus aureus, Salmonella sp. Escherichia coli, Shigella sp. and Klebsiella pneumonia.

\subsection{The Plasmid Size and Post Plasmid Curing Resistance Pattern of Selected Multiple Antibiotic Resistant Bacteria Isolated from Poultry Droppings}

Plasmid DNA was extracted and subjected to gelelectrophoresis, different bands were observed and the sizes based on interpretation and post plasmid curing resistance patterns were recorded in Table 1 . The result revealed that the plasmid size ranged from 8.60 to 128.00 kilobase pair (kbp) and the number of plasmid carried by bacteria ranged from 1 to 3 plasmids. Post plasmid curing antibiotic resistance pattern of the bacteria showed that the isolates are still resistant to at least two antibiotics. 
Table 1. The plasmid size and post plasmid curing resistance pattern of selected multiple antibiotic resistant bacteria isolated from poultry droppings.

\begin{tabular}{|c|c|c|c|c|c|}
\hline \multirow[b]{2}{*}{$\mathbf{S} / \mathbf{N}$} & \multirow[b]{2}{*}{ Bacterial Isolates } & \multirow{2}{*}{$\begin{array}{l}\text { Plasmid size } \\
\text { (kbp) }\end{array}$} & \multirow{2}{*}{$\begin{array}{l}\text { Source } \\
\text { (Location) }\end{array}$} & \multicolumn{2}{|l|}{ Phenotypic Resistance Pattern } \\
\hline & & & & Resistance patterns before plasmid curing & $\begin{array}{l}\text { Post plasmid curing } \\
\text { resistance patterns }\end{array}$ \\
\hline 1 & Proteus mirabilis & 10.00 & Broiler (D) & Aug Cro Nit Gen Amx Tet Cot & Cro Nit Cot \\
\hline 2 & Salmonella typhi & $24.00,48.20,70.00$ & Layer (D) & Aug Cro Nit Ofl Amx Cpx Tet Ch & Cro Tet Ch \\
\hline 3 & Pseudomonas aeruginosa & $8.60,34.00,70.00$ & Broiler $(\mathrm{H})$ & Aug Cro Nit Gen Ofl Amx Cpx Tet Cot Ch & Cro Nit Gen Amx Ch \\
\hline 4 & Staphylococcus aureus & 20.00 & Broiler (D) & Aug Cot Cxc Ery Gen Tet Ch & Ery $\mathrm{Ch}$ \\
\hline 5 & Salmonella sp. & $50.00,67.00$ & Broiler (G) & Aug Cro Nit Amx Cpx Tet Cot Ch & $\mathrm{Nit} \mathrm{Ch}$ \\
\hline 6 & Escherichia coli & $71.00,128.00$ & Broiler (A) & Aug Cro Nit Gen Ofl Amx Cpx Tet Cot Ch & Cro Gen Tet Cot \\
\hline 7 & Shigella sp. & 20.00 & Layer (A) & Aug Cro Nit Gen Amx Cpx Tet Cot Ch & Aug Cro Nit Ch \\
\hline 8 & Klebsiella pneumonia & $50.00,67.00$ & Broiler $(\mathrm{H})$ & Aug Cro Nit Ofl Amx Cpx Tet Cot Ch & Nit Tet Cot \\
\hline
\end{tabular}

KEY: AUG- Augmentin, CRO- Ceftriaxon, NIT- Nitrofuratoin, GEN- Gentamicin, OFL- Ofloxacin, AMX- Amoxicillin, CPX- Ciprofloxacin, TETTetracycline, COT- Cotrimoxazole, CH- Chloramphenicol, CXC- Cloxacillin, ERY- Erythromycin, A - FUTA, D - Ijoka, G - Alagbaka, H - Ondo road, kbp kilobase pair

\subsection{Molecular Identification of Selected Multiple Antibiotic Resistant Bacterial Isolates from Poultry Droppings in Akure}

Molecular identification of multidrug resistant Bacterial isolates from poultry droppings is presented in Table 2 . The length of amplified products was 1500 base pair. The sequence obtained was blasted in National Centre for Biotechnology Information (NCBI) database. Based on the 16s rRNA sequences, the following bacterium were confirmed Salmonella enterica subsp.enterica serovar Typhi str. CT18, Proteus mirabilis strain HI4320, Pseudomonas fluorescens SBW25, Staphylococcus cohnii subsp. cohnii strain 532 Contig16, Salmonella enterica subsp. enterica serovar Infantis, Escherichia coli str. K12 substr. DH10B, Shigella flexneri 2a str. $2457 \mathrm{~T}$ and Klebsiella pneumoniae strain J1. The result also revealed a difference in cultural identification of Staphylococcus cohnii subsp. cohnii strain 532 Contig16, Salmonella enterica subsp. enterica serovar Infantis and Pseudomonas fluorescens SBW25.

Table 2. Molecular identification of selected multiple antibiotic resistant bacterial isolates from poultry droppings in Akure.

\begin{tabular}{lllll}
\hline S/N & $\begin{array}{l}\text { Biochemical Characterization } \\
\text { of Selected Bacteria }\end{array}$ & 16s rRNA sequence identification of Selected Bacteria & $\begin{array}{l}\text { Max Identity } \\
\text { score }\end{array}$ & Accession number \\
\hline 1 & Proteus mirabilis & Proteus mirabilis strain HI4320 & $97 \%$ & NC010554.1 \\
2 & Salmonella typhi & Salmonella enterica subsp.enterica serovar Typhi str. CT18 & $100 \%$ & NC003198.1 \\
3 & Pseudomonas aeruginosa & Pseudomonas fluorescens SBW25 & $92 \%$ & NC012660.1 \\
4 & Staphylococcus aureus & Staphylococcus cohnii subsp. cohnii strain 532 Contig16 & $99 \%$ & NZLATV01000012.1 \\
5 & Salmonella sp. & Salmonella enterica subsp. enterica serovar Infantis & $80 \%$ & NZ LN649235.1 \\
6 & Escherichia coli & Escherichia coli str. K12 substr. DH10B & $100 \%$ & NC010473.1 \\
7 & Shigella sp. & Shigella flexneri 2a str. $2457 \mathrm{~T}$ & $100 \%$ & NC004741.1 \\
8 & Klebsiella pneumonia & Klebsiella pneumoniae strain J1 & $99 \%$ & NZ CP013711.1 \\
\hline
\end{tabular}

\subsection{Phylogenetic Tree Based on the 16S rRNA Gene Sequence Comparisons}

The DNA sequences were selected from the BLAST results and used as inputs for the phylogenetic tree reconstruction. The result of the sequence was aligned and Phylogenetic tree was constructed and given in Figure 1. The clustering pattern indicates the genetic and evolutionary relationship between eight bacterial species. Two clusters were generated; Pseudomonas fluorescens, Shigella flexneri, Escherichia coli, Klebsiella pneumoniae and Salmonella enterica subsp. enterica serovar Infantis are in cluster 1, Staphylococcus cohnii, Salmonella enterica subsp.enterica serovar Typhi and Proteus mirabilis are in cluster 2.

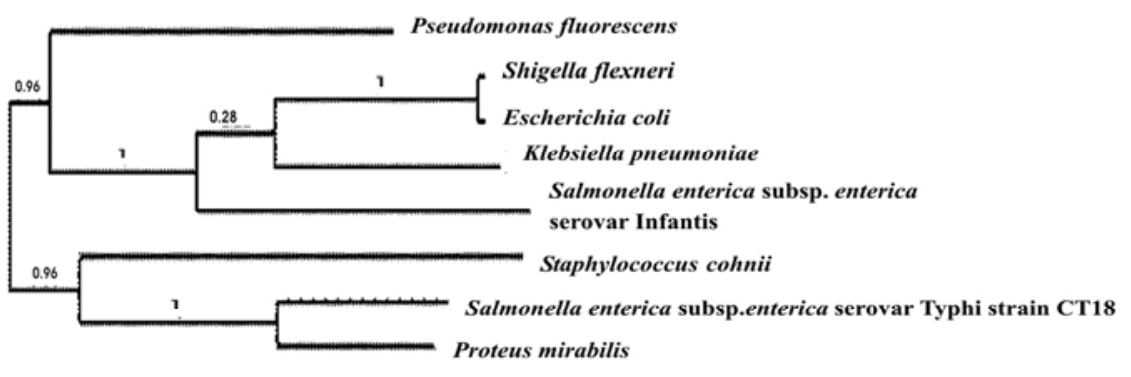

0.3

Figure 1. A Phylogenetic tree showing the degree of similarity of 16S rRNA sequence of multidrug resistant bacterial isolates. 


\section{Discussions}

In this study, bacterial strains were resistant to multiple antibiotics and some had more than one plasmid. All bacterial isolates harbour low or heavy molecular weight plasmid while some had both low and heavy molecular weight plasmid and are multi-drug resistance. These results are in agreement with the earlier studies which revealed that plasmids with large and low molecular size are responsible for high resistance in bacteria to antibiotics [16]. Also post plasmid curing resistance pattern revealed that multiple antibiotic resistance observed in these bacteria are plasmid mediated, these was also reported by $[17,18,19,20,21]$.

Worldwide, molecular approaches have emerged in clinical microbiology practices, molecular techniques have also been widely used in surveillance, mutation and other genetic studies of foodborne pathogens to increase our understanding into the primary source of foodborne pathogens, source of infection and genetic diversity. Molecular techniques have the advantage that, they are rapid, less laborious, and more sensitive, specific and efficient compared to the conventional method $[8,9]$. Molecular method also provides insights into etiologies of infectious disease [22, 23] and appropriate antibiotic treatment [24]. PCR revealed that the molecular weight of the genomic DNA of sequenced bacteria is $1500 \mathrm{bp}$. According to the $16 \mathrm{~S}$ rDNA analyses, selected multiple antibiotic resistant isolates showed more than $80 \%$ similarity in the NCBI GenBank by BLASTn. Based on the BLASTn results the isolates confirmed are Salmonella enterica subsp.enterica serovar Typhi str. CT18, Proteus mirabilis strain HI4320, Pseudomonas fluorescens SBW25, Staphylococcus cohnii subsp. cohnii strain 532 Contig16, Salmonella enterica subsp. enterica serovar Infantis, Escherichia coli str. K12 substr. DH10B, Shigella flexneri 2a str. 2457T and Klebsiella pneumoniae strain J1. The result also revealed a difference in cultural identification of Staphylococcus cohnii subsp. cohnii strain 532 Contig16, Salmonella enterica subsp. enterica serovar Infantis and Pseudomonas fluorescens SBW25. This was also reported by [25], who reported differences in conventional method and molecular method of bacteria identification. However, the results of this work demonstrate clearly the interest and feasibility to introduce the $16 \mathrm{~S}$ rDNA gene sequencing method in identification of human pathogenic bacteria of poultry origin in Akure, combination of conventional techniques and molecular approach will improve bacteriological diagnosis and allow specific and efficient identification of pathogenic bacteria and save human lives.

\section{Conclusion}

Multidrug resistant isolates habours plasmid which is of low or heavy molecular weight plasmid or both, resistance to ciprofloxacin and ofloxacin were found to be plasmid mediated. The molecular method of identification was found to be advantageous as bacteria were identified to strain level with the following bacteria of medical importance identified; Proteus mirabilis strain HI4320, Salmonella enterica subsp.enterica serovar Typhi strain CT18, Pseudomonas fluorescens SBW25, Staphylococcus cohnii subsp. cohnii strain 532 Contig16, Salmonella enterica subsp. enterica serovar Infantis, Escherichia coli str. K12 substrain DH10B, Shigella flexneri 2a strain $2457 \mathrm{~T}$ and Klebsiella pneumoniae strain J1. Finally, antibiotic used in poultry may have led to the occurrence of multiple antibiotic resistant bacteria and occurrence of plasmid mediated multiple resistant antibiotics especially fluoroquinolones, in pathogenic bacteria of poultry origin in Akure is of great public health concern.

\section{References}

[1] Adzitey, F. and Nurul, H. (2011). Campylobacter in poultry: incidences and possible control measures. Research Journal of Microbiology. 6: 182-192.

[2] Adzitey, F., Huda, N. and Gulam, R. (2011). Comparison of media for the isolation of Salmonella (XLD and Rambach) and Listeria species (ALOA and Palcam) in naturally contaminated duck samples. International Journal of Food Safety. 13: 20-25.

[3] Apata, D. F. (2009). Antibiotic Resistance in Poultry. International Journal of Poultry Science. 8 (4): 404-408.

[4] Collignon, P. (2009). Resistant Escherichia coli - We Are What We Eat, Clinical Infectious Diseases, 49: 202-204.

[5] Hammerum, A. M. and Heuer, O. E., (2009). Human health hazards from antimicrobial-resistant Escherichia coli of animal origin, Clinical Infectious Diseases, 48: 916-921.

[6] Nahar, A., Siddiquee, M., Nahar, S., Anwar, K. S. and Islam, S. (2014). Multidrug Resistant-Proteus Mirabilis Isolated from Chicken Droppings in Commercial Poultry Farms: Biosecurity Concern and Emerging Public Health Threat in Bangladesh. Journal of Biosafety and Health Education. 2: 120-128.

[7] Brindha, V. and Ani, A. M. (2012). Molecular characterization and identification of unknown bacteria from waste water. Indian Journal of Innovations and Development. 1(2): 87-91.

[8] Magistrado, P., Carcia, M. and Raymundo, A. (2001). Isolation and polymerase chain reaction-base detection of Campylobacter jejuni and Campylobacter coli from poultry in Philippines. International Journal of Food Microbiology. 70: 194-206.

[9] Keramas, G., Bang, D. D., Lund, M., Madsen, M., Bunkenborg, H., Telleman, P. and Christensen, C. B. V. (2004). Use of culture, PCR analysis and DNA microarrays for detection of Campylobacter jejuni and Campylobacter coli from chicken faeces. Journal of Clinical Microbiology. 47: 3985-3991.

[10] Okeke, I. N., Fayinka, S. T. and Lamikanra, A. (2000). Antibiotic resistance in Escherichia coli from Nigerian students, 1986 1998. Emerging Infectious Disease. 6: 393396. 
[11] Zhang, R., Eggleston, K., Rotimi, V., and Zeckhauser, R. J. (2006). Antibiotic resistance as a global threat: evidence from China, Kuwait and the United States. Global Health 2: 61-69.

[12] Cheesbrough, M. (2006). District Laboratory Practice in Tropical Countries. 2nd Edition., Cambridge University Press, Cambridge, UK., ISBN-13:9781139449298. 50: 165-176.

[13] Committee for Clinical Laboratory Standards, (2014). Performance Standards for Antimicrobial Susceptibility Testing; Twenty-Fourth Informational Supplement. CLSI document M100-S24 Wayne, PA: ISBN 1-56238-898-3. 34(1): 50-98.

[14] Liu, P. Y., Lau, Y. J. and Hu, B. S. (1995). Analysis of clonal relationships among isolates of Shigella sonnei by different molecular typing methods. Journal of Clinical Microbiology, 33: 1779-1783.

[15] Nicole, J. M., Zhilong, G. and Xing-fung, L. I. (2004). Reverse Transcription- multiplex PCR Assay for Simultaneous Detection of E. coli 0157:H7, Vibrio cholera O1 and Salmonella typhi. Journal of Clinical Chemistry, 50: 20372044.

[16] Kariuki, S., Gilks, C., Kimari, J., Obanda, A., Muyodi J., Waiyaki, P. and Hart, C. (1999). Genotype analysis of E. coli strains from children and chicken living in close contact, Applied and Environmental microbiology, 65(2): 472-476.

[17] Parkhill, J., Dougan, K. D., James, N. R., Thomas, D., Pickard, J., Wain, C., Churcher, K. L., Mungall, S. D., Bentley, M. T. G., Holden, M. et al., (2001). Complete genome sequence of a multiple drug resistant Salmonella enterica serovar Typhi CT18. Nature 413: 848-852.

[18] Khan, A. U. and Musharraf, A. (2004). Plasmid-mediated multiple antibiotic resistance in Proteus mirabilis isolated from patients with urinary tract infection. Medical Science Monitoring. 10(11): 598-602.
[19] Nsofor, C. A. and Iroegbu, C. U. (2013). Plasmid profile of antibiotic resistant Escherichia coli isolated from domestic animals in South-East Nigeria. Journal of Cell and Animal Biology. 7(9):109-115.

[20] Ajayi, A. O. and Egbebi, A. O. (2011). Antibiotic sucseptibility of Salmonella Typhi and Klebsiella Pneumoniae from poultry and local birds in Ado-Ekiti, Ekiti-State, Nigeria. Annals of Biological Research. 2 (3):431-437.

[21] Gundogan, N. and Avci, E. (2013). Prevalence and antibiotic resistance of extended-spectrum beta-lactamase (ESBL) producing Escherichia coli and Klebsiella species isolated from foods of animal origin in Turkey. African Journal of Microbiology Research. 7(31), 4059-4064.

[22] Clarridge III, J. E. (2004). Impact of 16S rRNA gene sequence analysis for identification of bacteria on clinical microbiology and infectious diseases. Clinical Microbiology. 17: 840-862.

[23] Woo, P. C. Y., Lau, S. K. P., Teng, J. L. L., Tse, H., and Yuen, K. Y. (2008). Then and now: use of $16 \mathrm{~S}$ rDNA gene sequencing for bacterial identification and discovery of novel bacteria in clinical microbiology laboratories. Clinical Microbiology and Infection. 14: 908-934.

[24] Harris, K. A., Fidler, K. J., Hartley, J. C., Vogt, J., Klein, N. J., Monsell, F. and Novelli, V. M. (2002). Unique case of Helicobacter sp. osteomyelitis in an immunocompetent child diagnosed by broad-range 16S PCR. Journal of Clinical Microbiology. 40: 3100-3103.

[25] Frickmann, H., Dekker, D., Schwarz, N. G., Hahn, A., Boahen, K., Sarpong, N., Adu-Sarkodie, Y., Halbgewachs, H., Marks, F., von Kalckreuth, V., May, J. and Hagen, R. M. (2015). 16S rRNA Gene Sequence-Based Identification of Bacteria in Automatically Incubated Blood Culture Materials from Tropical Sub-Saharan Africa. PLOS ONE | DOI:10.1371/journal.pone.0135923: 1-20. 